\title{
To Research the Advantages and Limitations of AI based App in the Indian context for the Visually Challenged
}

\author{
Smita Santoki, Neha Patvardhan
}

\begin{abstract}
Artificial Intelligence (AI) is going to be the frontrunner in any of the modern day communication going forward and so this research is done to find out how AI helps in visual imagery recognition for enhancing the accessibility of the visually impaired through apps like AI poly AI for recognizing people, texts, objects and colors.
\end{abstract}

40 visually impaired from the Atmadeepam Society (Nagpur, India) who are computer literate and smart phone users considered for the study through the mixed methods research where quantitative analysis is done

In addition, Qualitative analysis through Phenomenology method is done

Almost 80 percent of the low vision respondents are in favor of these accessibility apps being completely helpful whereas the rest have faced certain inconvenience due to these apps in functioning.

From the findings, it is evident that these visually impaired people are extremely happy in using these accessibility tools to overcome their navigation challenges and also get value added quotient added to their knowledge through the text feature of these AI enabled apps

On the other hand, research finding also shows a set of people who are not convinced fully with the AI based apps functioning. These were typically based on incorrect object identification, difficulty in understanding the accent and lacks the facility for regional language converter

The visually impaired will be better equipped to function due to raised confidence, positive attitude and thereby gaining a place in the society as active contributors to the economy that will assist in disability integration

The paper attempts to study the modern AI accessibility apps especially related to object recognition in the Indian context for the visually impaired

Keywords: Artificial Intelligence (AI), App(s), Image Recognition, accessibility, Visually Impaired and Indian context

\section{INTRODUCTION}

In their preface of the book titled 'Zero to One' Peter Thiel and Blake Masters mention, "The next Bill Gates will not build an operating system. The next Larry Page or Sergey Brin won't make a search engine.'This is so true as technological advancements cannot happen on repeating things but on creating something new, innovative and a tremendous breakthrough that reaches the grassroots level and can be of practical use.

Progress like these can be of 2 forms, namely the Horizontal (extensive) and Vertical (intensive) ones. Copying things that work example- Globalization is a

Revised Manuscript Received on April 12, 2019.

Smita Santoki,Assistant Professor, Symbiosis Institute of International Business, Pune; India. (smita.santoki@siib.ac.in)

Dr. Neha Patvardhan,Assistant Professor, Symbiosis Institute of International Business, Pune; India. (neha.patvardhan@ siib.ac.in) horizontal progress whereas doing new things exampleTechnology is a vertical progress.

Quantum computing is today what Artificial intelligence was 20 years back. Industry 4.0 is driven by many factors and artificial intelligence plays a pivotal role in this. (Business Today Magazine, January 2019 issue)

However, when it comes to people with special needs, superior technology is still a distant dream especially in the Indian context.

It is evident that these people do have access to apps that eases their accessibility in their indoor and outdoor mobility but these apps too come with their set of limitations in the Indian sense.

In line with these tectonic shifts in the artificial intelligence phases, this paper attempts to find out the effects of these apps on the Indian visually disabled with reference to their daily accessibility.

Historically speaking there are many AI based Image Recognision Apps available (e.g. AppleVis)for the visually impaired; however in the recent times $\mathrm{AI}$ has technologically advanced and entered in to the active phase of building objects recognition apps for the efficient accessibility of the people with special needs.

Therefore, it is of prime importance to study the usability of such image recognizing apps like AI poly for the Indian visually disabled.

\section{LITERATURE REVIEW}

Cognitive technologies is of the most practical relevance for accessibility to be successful. Moreover, this gets a double whammy if not done well in case of the blind. Everything right from their first step indoors to moving out depends on a guide; be it in the form of a sighted person, a walking cane or the modern day mobile gadget streaming with latest updated apps.

A report by Accenture says, "AI has the potential to add $\$ 957$ billion or $15 \%$ of current gross value added, to India's economy in 2035."

According to a paper by research firm IDC and storage company Seagate, "Global data will grow from 33 zetabytes (1ZB is 1 trillion gigabytes) in 2018 to $175 \mathrm{ZB}$ by 2025 . The accuracy of AI systems increases with larger amounts of data. And given its large population and massive amounts of data, India is a fertile ground for developing better AI systems." (Business Standard newspaper article dated 30 Jan 2019)

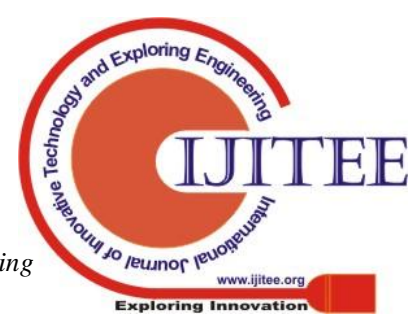


Research provides various insights to know a visually impairer's challenges. Like (Melarkode, 2014) "using a scenario-driven, ontological and goal-oriented approach. Inhouse testing conducted revealed that collaborative approach may indeed provide added comfort during indoor navigation."

Or the paper by (Liao, 2016) where they have mentioned about the differences in the sighted people and the visually challenged with reference to their spatial perception where the VI person usually face physical as well as information barrier. For their accessibility, mobility and confidence boosting, the researchers have given stress on improving the transport system and thus have come up with a mobile accessible information system that allows visually challenged people to receive information related to their transportation at key junctions.

They came up with a personal assistive system based on a smartphone called MAPS (Mobile Accessible Pedestrian System), that provides intersection geometry and signal timing information. "Research has been carried out through smart phone application to support visually impaired pedestrians at signalized intersections crossings" (Liao, 2013)

We also appreciate the work done by (Rahman \& Hassan, 2002) where they address the aid for visually impaired and blind people for portable mobility. The aim of the research is to find out a matching algorithm for object detection for moving image sequences.

Another algorithm based study is done by (Tumkur \& Subbiah, 2012) on Pedometers. These devices consist of measuring distance covered by the number of steps taken by an algorithm. Further accelerometer wise they have worked upon the results to find out any differences with respect to currently existing models.

Another attribute about the visually impaired is about their physical activity studied by (Marmeleira, Laranjo, Marques, \& Pereira, 2014) where they compared them to the sighted people with the help of the accelerometers to monitor their daily physical activity for one week. They concluded that there was no difference in gender and that the body mass index not associated with physical activity. Their conclusion gives health promotion strategies required for the visually handicapped as they have low levels of physical activity.

Alternatively, a study done by (Paisios, 2012) the researchers present a simple to use mobile navigational guide for the visually challenged in their indoor navigation set up. Another work by them in the Mobile Brailler that has the prototypes to enter text to a mobile smart phone that is based on the Braille alphabet. Then they have worked in getting currency bills readable tool easily by the disabled. And have also worked on their ease of understanding the color combinations to be worn.

Internationally speaking, plethora of work is available on AI based Apps related to accessibility for the visually impaired community; however very negligible data and work exists in the Indian context; especially for the image recognition apps that the blinds of Indian soil may require.

Varun Aggarwal of Aspiring Minds points out so well when he says," The country's diversity of languages, dialects, accents, scripts, dress and culture presents a rich set of challenging problems for AI. Current AI techniques are limited in their ability to handle complexity, and they will have to mature to deal with the diversity of life in India."

Our study aims at investigating whether a visually impaired person is comfortable using the AI poly app and if the image recognition feature is of good use to them in the Indian set up.

In accord with the same, there have been studies and research undertaken; however big breakthroughs are required to be done in the Indian context as only one app so far is trying to manage to suit the needs of the Indians concerning the object recognition app.

The above-mentioned app is the pioneer innovation undertaken by Accenture Labs, Accenture; India. This app is launched just the last year and is still in its pilot phase. Moreover, it has studied in general and yet to be tested for people with special needs. "Drishti leverages latest artificial intelligence (AI) technologies, including natural language processing, image recognition, optical recognition, and smart glasses to help visually-impaired persons perceive the world around them like never before." (Kapur 7 Kapur, 2014)

Thus, our research paper is uniquely strategized at finding out the limitations of this app in identifying the local Indian words for the objects recognizing feature and suggestions accordingly to improvise it.

\section{RESEARCH GAP}

Past research is focusing on the accessibility on navigation, mobility, walking speed, physical activity, touch screen braille texts etc.

However, the element missing in the past research is AI apps studied from the visually challenged point of view; especially in their object recognition experience with the app for both indoor as well as outdoor mobility. Our research paper has identified this gap and attempted to work for the same.

\section{OBJECTIVES}

a. To investigate the effects of 'image recognizing' algorithms (image recognition based AI poly App) for accessibility of the visually impaired in India

b. To study the limitations of the object recognizing apps

c. To enlist possible suggestions that can be done to improve the object recognition app AI poly in the Indian context

\section{HYPOTHESIS}

a. H0 - Indian Visually impairedare satisfied using the image recognition based AI Poly app

b. H1 - Indian Visually impairedare not satisfied using the image recognition based AI Poly app 


\section{METHODOLOGY}

\subsection{Research Methodology}

To understand the breadth and depth of the research problem, researchers have used the mixed method technique, which comprises both quantitative and qualitative methods of data collection.In this study, researchers have attempted to analyze the usability of the object recognizing mobile APP (AI Poly) for the visually impaired users. The usability tested through the perceived value of the users, by capturing the data from both quantitative and qualitative methods.

For the quantitative technique, data collected through a questionnaire relating to the efficiency of the AI Poly APP for its object and text-recognizing feature.

On the other hand, for qualitative technique, data collected through the Phenomenology method in which verbatim were recorded with respect to their experiences and reactions about this APP.

The study is on a focused group, which comprises of visually impaired smartphone users in the age group of 1840. The reason for performing such an experiment on focused group is to circumvent the techno savvy heterogeneities of the VI smartphone users. The experiment conducted with each participant for a week is divided into three phases. In each phase, some tasks assigned to the Visually Impaired (VI) Participants

\section{Phase I (One day training)}

One day briefing of this iOS based AI Poly APP provided to each participant from the focused group consisting of 40 users. The focused group users selectedfrom the "Atmadeepam Society" Nagpur. This society works for the visually impaired people and provides training related to the different computer accessing software's like JAWS, voice over etc.

The focused group selected for this study, comprised of 16 female and 24 male young adults, who are regular as well as systematic smartphone users.

The participants made familiar with the different object, text and color recognition features as well as they were updated to the comprehensive settings of this App. During this phase, a pilot run-through has been carried out on the random objects, just to validate whether they have accustomed to this APP.

Phase II (5 days exposure to the AI poly APP for both indoor-outdoor mobility)

In this phase, the participants were asked to use the AI Poly APP for five days. According to a Google survey, "to get a hang of any mobile APP", the recommended usability time is 90 minutes. Therefore, in this experiment the users were asked to use the APP at least for 90 minutes every day. In doing so, the total usability timewas 7.5 hours ( Each day 90 minutes for 5 days : $90 * 5 \_-=450$ minutes).

In this part of the experiment, the participants have used this APP for their routine navigation and were asked to recognize all types of objects and its related text and color. For noting the accuracy of the APP, for its correct identification of the objects, text and color, all the participants were escorted by a sighted person throughout this phase.
Also to maintain the homogeneity in the types of objects, to which the users were exposed, they have been categorized as follows:-
a. Personal Care objects
b. Labelling on medicines and health care monitoring systems
c. Time keeping Tools
d. Alarming tools
e. Food preparations
f. Consumption utensils
g. Currency and finance operations

In this stage of the experiment, the researchers ensured that the participants are exposed to all the above-mentioned categories of the objects.

Phase III (One day for collecting AI poly App response \& feedback)

In this last phase of the experiment, both quantitative and qualitative methods (mixed method) is used for data collection. In the quantitative technique, data is collected from both the participants as well as from their sighted counterpart who accompanied them for the app's feedback for its efficiency and accuracy.

The feedback related to the App is gaged on the following constructs, using a Likert scale:

1. Ease of Appnavigation and exploration

2. Swift Switching over to the other menufor different object categories

3. Comprehensiveness of the settings

4. Accuracy in Object, text and color recognition

5. Time lag in navigation

6. Speediness of the APP

Feedback from the sighted escorted person is according to the different category of objects as follows:-

1. Correct identification of the personal Care objects

2. Correct identification of the labelling on medicines and health care monitoring systems

3. Correct identification of the time keeping Tools

4. Correct identification of the food preparations

5. Correct identification of the consumption utensils

6. Correct identification of the currency and finance operations

\section{Sample Size}

We assume that the sample size 40 is normal because we have restricted our study to visually impaired persons who are computer literates and smart phone users. Secondly, the existing literature reviewed has sample size ranging from 19 to 31 and therefore we have considered $25 \%$ enhanced sample size

\section{Scale Validation}

. When the scale was tested for internal reliability and validity; the Cronbach alpha $=0.61$

For the qualitative analysis, the verbatim relating to the feedback and suggestions for an improvement in the App in the Indian context were recorded and have been analyzed in the Data analysis and interpretation 


\section{DATA ANALYSIS \& INTERPRETATION RESULTS}

\subsection{Ease of App navigation and exploration}

$83 \%$ of the visually impaired respondents are 'very easy' in using the said app in terms of ease of app navigation and exploration. This reflected through the likert scale of difficulty.

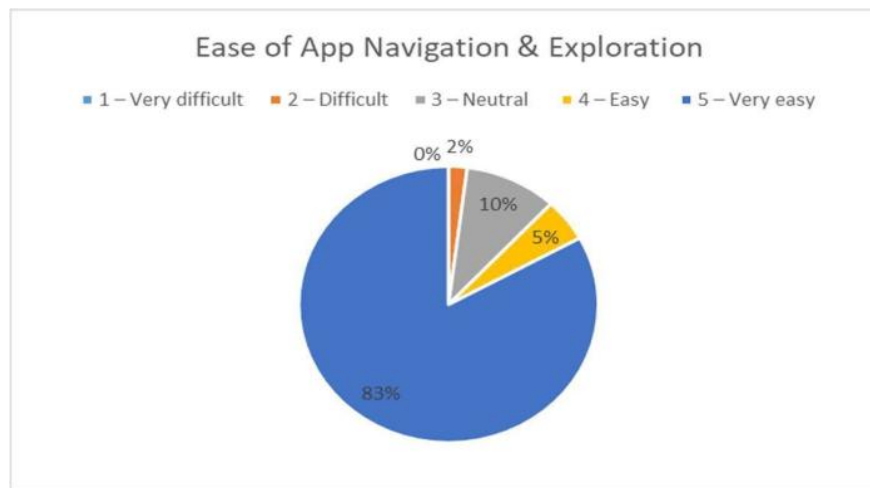

Fig. 1.

7.2. Swift Switching over to the other menu for different object categories (Menu Navigation Comfortness)

$80 \%$ of the visually disabled were 'very comfortable' in surfing through the different menu categories for object identification.

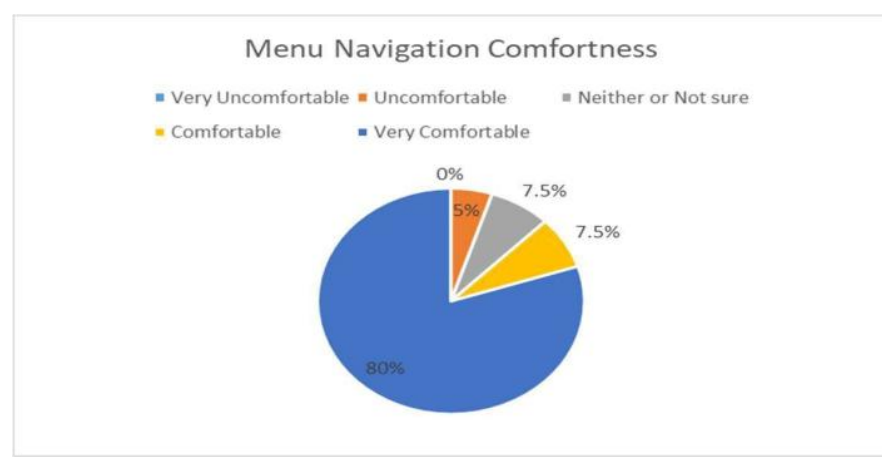

Fig. 2.

\subsection{Comprehensiveness of the settings}

$90 \%$ of these could fully comprehend the various settings available in the app. This is done by likert scale of difficulty- 'very easy.'

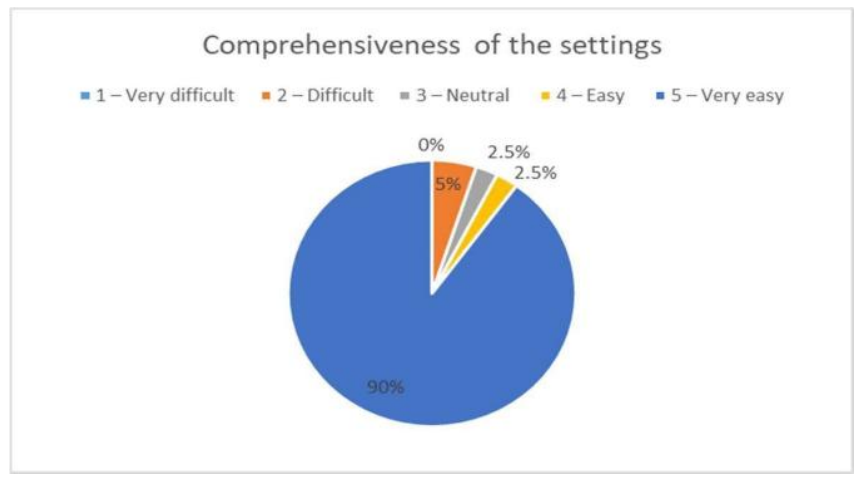

Fig. 3.

\subsection{Accuracy in Object, text and colour recognition}

A five point Likert scale to find the likelihood of the correct identification of the object recognition from the app in the Indian scenario done for the following categories through the sighted persons and the analysis is as below:

For Personal care objects

$80 \%$ of the app was 'almost always true' for the correct object identified

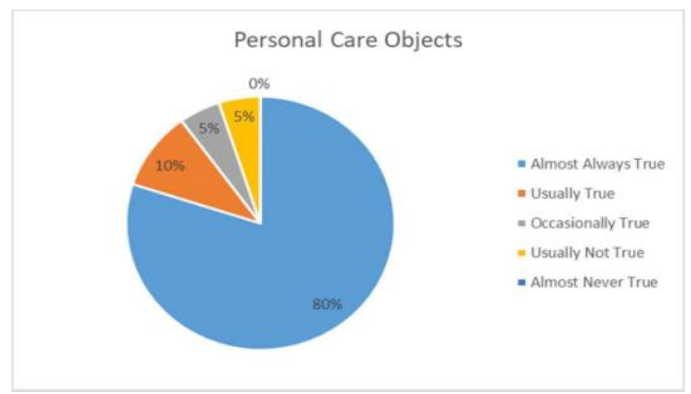

Fig. 4.

Labelling on medicines and health care monitoring systems

$80 \%$ of the app was 'almost always true' for the correct object identified.

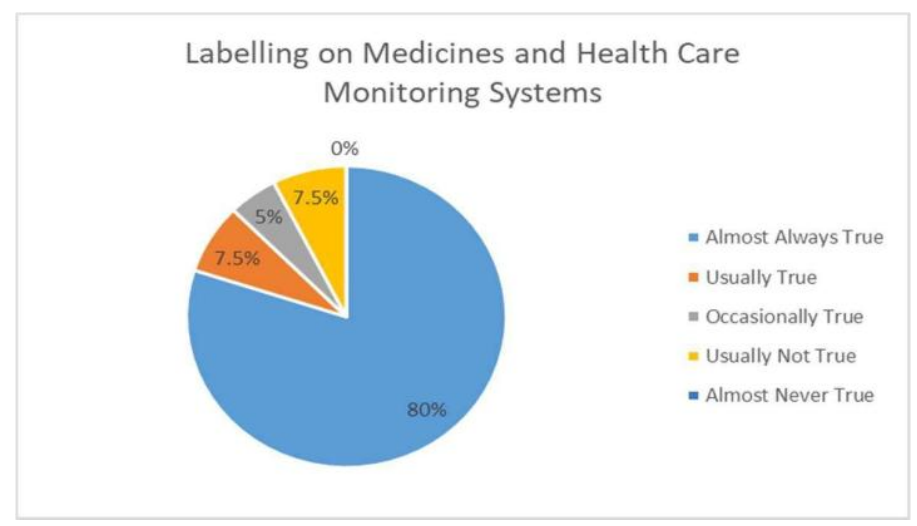

Fig. 5.

The time keeping Tools

$90 \%$ of the app was 'almost always true' for the correct object identified.

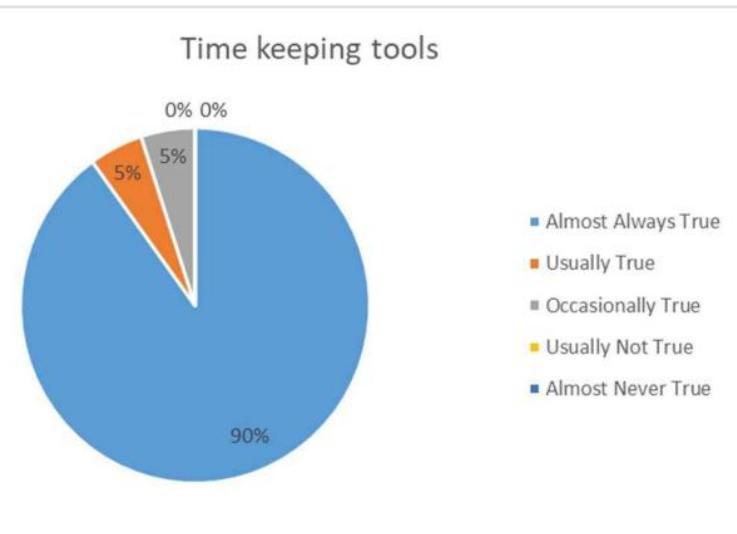

Fig. 6.

Published By: 
Food preparations

$65 \%$ of the app was 'almost always true' for the correct object identified

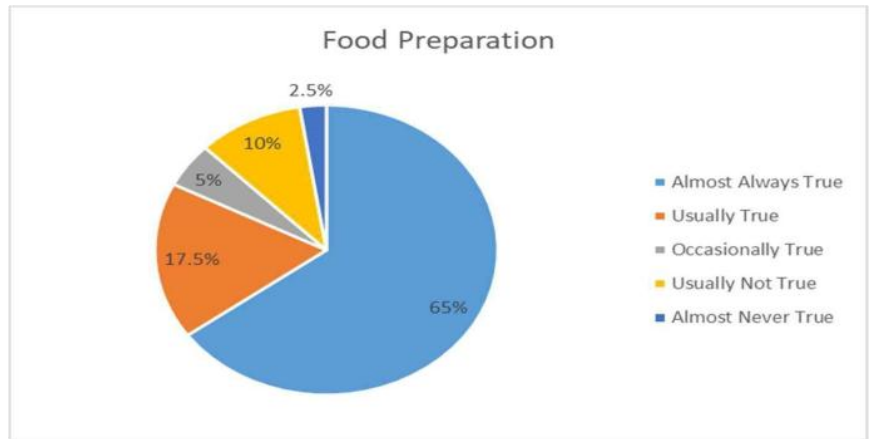

Fig. 7.

Interesting Examples of food recognition-

In some of the cases, the app showed food items similar to the one under scanner but not the exact one. For example: it read out 'bread' for the Indian 'roti' and 'Cheese' for Indian 'chutney'

We also have the snap shots for the same as posted below:

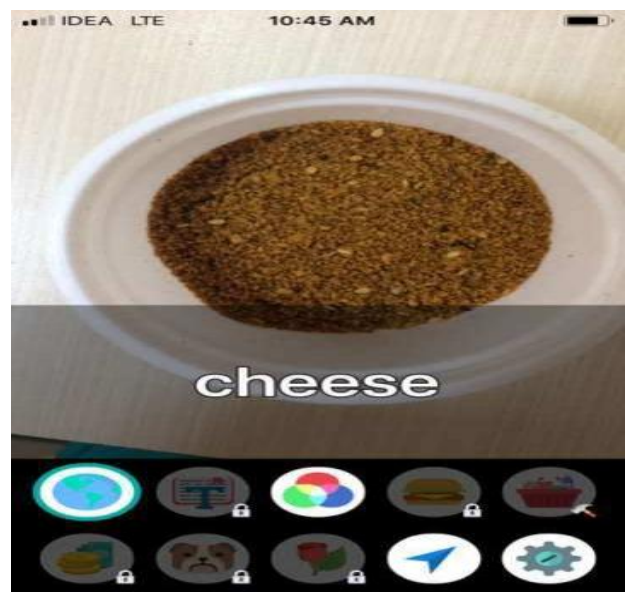

Fig 8. Cheese for Chutney

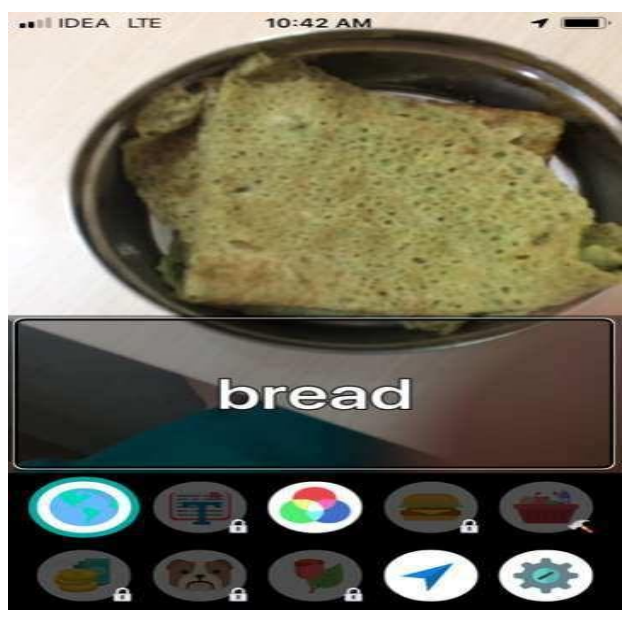

Fig. 9. Bread for Roti

Consumption utensils

$63 \%$ of the app was 'almost always true' for the correct object identified

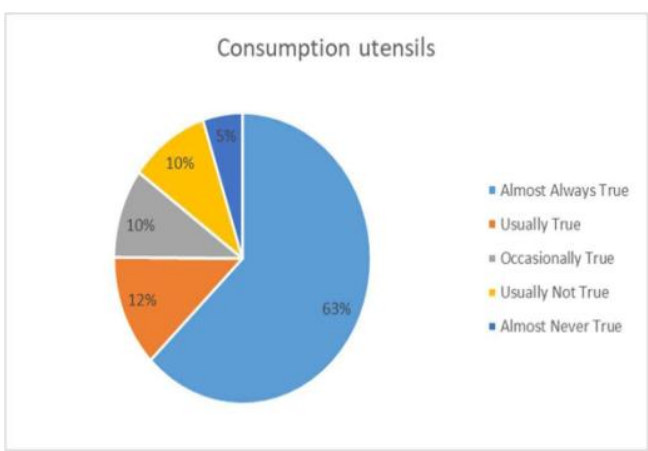

Fig. 10.

Currency and finance operations

$93 \%$ of the app was 'almost always true' for the correct object identified

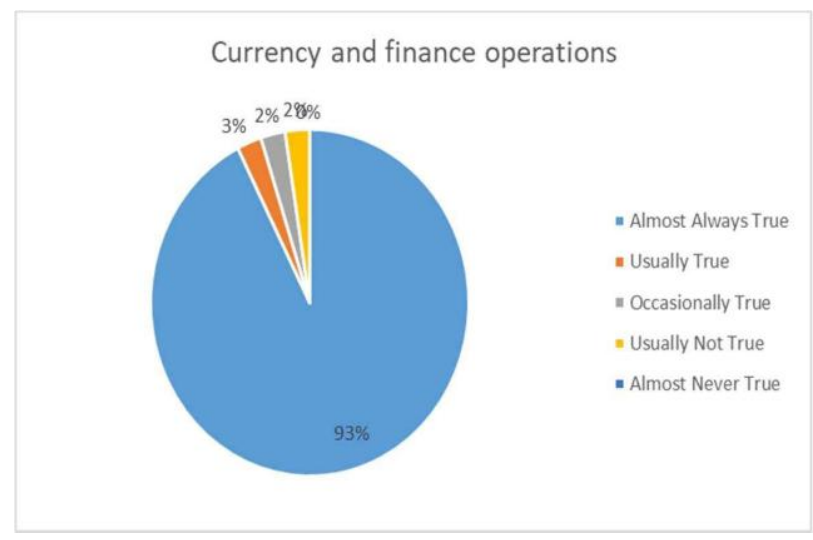

Fig. 11.

\subsection{Time lag in navigation}

Five point Likert scale with reference to frequency is seen for the time lag for navigation- where $88 \%$ of the respondents had never faced any time lag.

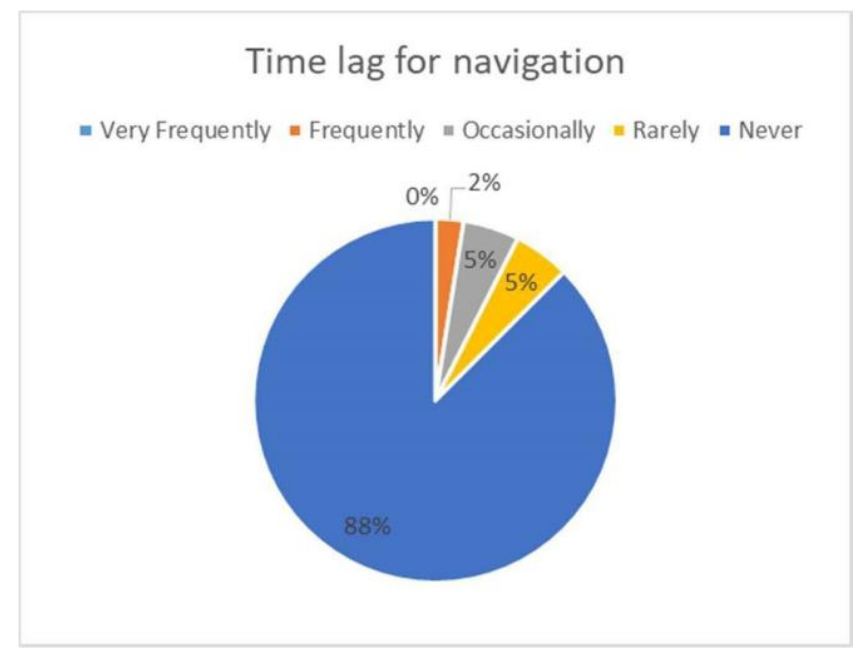

Fig. 12.

\subsection{Speediness of the APP}

Five point Likert of satisfaction was gaged for the speediness of the app- 93\% were 'very satisfied'.

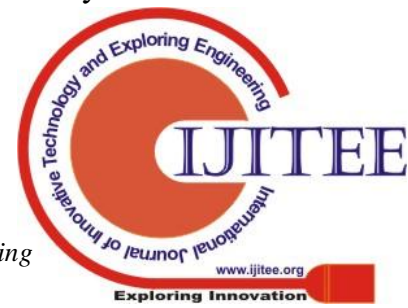




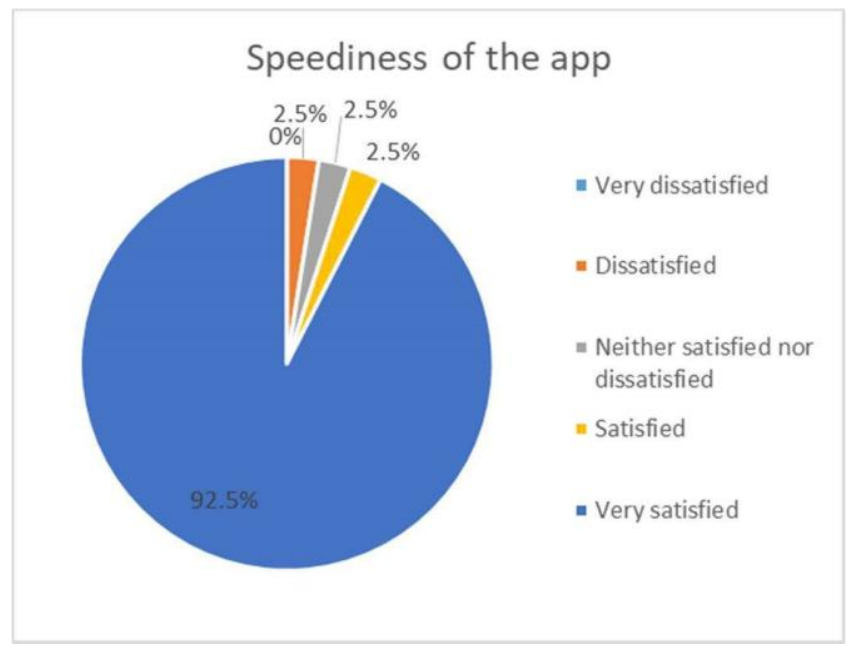

Fig. 13.

\section{ANALYSIS THROUGH VERBATIM}

From the above analysis, it is clear that in terms of identifying, the correct object is a challenge in the Indian sense and this is further validated with the phenomology method undertaken through verbatim from the respondents:

- Sonali, 20yrs:. "I cannot understand the accent of the voice assistant who guides me through the app; so I want someone to replace her with a language that I can understand."

- Dilip, 26yrs: "It was a very useful experience to know how I can do things faster with this app. I wish to use this app daily now for my navigation purpose.".

- Mayur, 28yrs: "I made the right choice by downloading the AI poly app, post our research experience at Anandeepam. This app has simplified my life from the various day-to-day challenges I encountered earlier due to my disability. Now, not only am I able to function smoothly, both indoors and outdoors with this AI ply but I have gained good vocabulary through the app."

- Geeta, 18yrs: "I cannot afford the iOS phone right now but thanks to your experiment time that I could see how usefully this works. The app is very user friendly and provides the switching off different menu settings faster."

- Parikshit, 21yrs: "I didn't know this AI poly app to be so useful to us. I have used both its text recognition feature as well as the object recognition app and find both of them extremely beneficial."

- Apeksha, 20yrs: "Initially I thought this app will be of limited help but when I tested it every day regularly for a week, got to know its features and applications in details. The only big limitation I find in this app is that it is unable to identify our Indian grocery items like lentils, flour, pickles etc and so I want to suggest that they can work on an algorithm that picks up vernacular languages also so that this is a convenience tool that can be used in the Indian context."

- Sneha, 21yrs: "I am skeptical about this app as I feel this is not made for people of India. The other day, I could not get 'amrutanjan' (an Indian name for a balm that cures headache) for my grandmother when she asked me to get it. The object recognition simply could not understand what the object was and kept on beaming, 'am not sure' so they must make the app user friendly in the Indian context.".

- Kapil, 24yrs: "it is my pleasure that I was a part of this study. My teacher and the researchers explained us the app functioning very clearly. I could use it well for a week of the study. I have bought the apple phone and downloaded the AI poly app that will now ease out my daily functioning significantly. I can now mix with my sighted friends with comfort."

- Kunal,38yrs \& Savita,36yrs: "The object recognition tool failed to guess our staple Indian food items like 'rotis', 'daal', 'sabzi', 'chawal' etc. and we had tough time serving the same to our guests. The AI systems must work upon an app that will have Indian objects recognized."

- Nimisha, 31yrs: "Food items, medicines and few household Indian items are not recognized by the object recognition app so such research must happen in the Indian set up to benefit people like us."

- Prerna,30yrs: "This app is not very useful for us as mainly we need app for identifying the objects we use for day to day activities so except for a few objects, majority of our Indian things are not recognized by app."

- .Neelam, 19yrs: "There are many accessibility apps available for us in the market but this one is great in terms of speed in speech texts recognition but lacks object recognition for us Indians.".

- Yatin, 21yrs: "Customization to vernacular Indian languages needed for us to in terms of object recognition app so that we can decipher the signals, objects and various texts easily."

- . Sana, 20yrs: "I find a lot of difficulty in understanding the signboards as the App does not read out my vernacular language (Marathi) and thus causes a lot of hindrance in outdoor mobility.".

- Zubin, 22yrs: "I could not pick up the band aid as it could not identify the local name."

- Yamini, 23yrs: "The App could not read out the vernacular newspaper text to me and so I could not participate for an essay competition.".

- Lata, 24yrs: "AI App is of significant importance to visually challenged people like us because we get a feeling of someone accompanying us for our daily navigation purpose and acts as a strong catalyst for connecting us to the general public."

- Parag, 40yrs: "Although late, but I am glad I got to know this App that is not only useful but has given an opportunity to use and provide our feedback to the researchers."

- Asha, 39yrs: "Accessibility Apps like these are required to be customized to the Indian customers need so that the Company can get access to one of the largest markets in the world."

- Akhil, 23yrs: "I look forward to use this App for the next six months and come up with a lot of possible ideas to improvise it to suit the Indian conditions." 
Therefore, Hypothesis H0 cannot be rejected as almost $80 \%$ of the respondents are satisfied with the app usage.

\section{FINDINGS \& SUGGESTIONS}

The major findings that emerge from the analysis is that the artificially intelligent based AI Poly app is overall a very useful resource for the visually challenged with a setback found majorly in their object recognition feature only in the Indian context.

High customization is the relevant need of the hour for the app like AI Poly to suit the specific local needs of the visually disabled when they need the object recognition app to give out the exact Indian version of the products especially in the food and consumption utensils category.

For instance, when an Indian blind wants to know the medicines available locally, the app based guide prompts as 'Not sure' and this happens repeatedly for many Indian products in food, grocery items, personal care, health care as well as the sign boards while he/she moves outside.

In this study, it is observed that almost $80 \%$ of the participants were satisfied with almost all the parameters undertaken for the study, namely

a. ease of app navigation and exploration

b. Swift switching over to other menus for different object category

c. Comprehensiveness of the settings

d. Time lag for navigation

e. Speed of the app

Except for the object recognition feature where only the food and the consumption utensils category has not much clarity as compared to the other categories under objects recognition tabs and this is clearly so in the Indian local cases.

Verbatim collected through phenomology method also reflected the above findings through the observations, suggestions and feedback by the focused group.

Therefore, we would like to suggest probable solutions for the pain points of the Indian visually impaired that needs to be urgently addressed to by the AI based app developers, technocrats, technical experts and such decision makers. Our suggestions are as follows:

They need to add the Indian image repository to the app especially the food segment and the consumption utensils section

As per the snap shots provided under findings, few Food items identified by the object recognition app is not the exact one but falls under the food items category itself. Thus, our suggestion is to improve this by adding food image repository

For vernacular Indian languages to be identified by the voice assistants, the AI and the deep learning algorithms should bring a smart curation of content in their regional languages for example: Sign boards instructions in local language

And vernacular Indian language translations similarly for the text recognition feature also required

\section{LIMITATIONS \& FUTURE SCOPE FOR RESEARCH}

The research is limited to the AI Poly app and not the other smartphones apps. Secondly, the study is restricted specifically to the needs, usage and limitations for the Indian visually challenged persons. The researchers also had limitations to the subjects involved as they have limited it to the number as 40 .

Limitations however pave the way for the future scope of research in a way and so this research work can be extended to a larger group of data. This can be extended to the education of such people through incorporating this to Education 4.0.and if this works for them in the Indian context, this research can be extended to the other similar neighboring countries having similar cultures and contexts.

\section{CONCLUSION}

The past is not an indicator to the future because the progress and the growth story in AI, machine learning, computing power and robotics have changed the way things are done in the most dramatic way. The accessibility landscape is going strong but needs a lot of rework in the Indian context.

AI poly need not reform but needs to transform and weave the matrix in such an algorithm that it will be perfectly applicable to Indian roots.

The efforts taken by the team at Apple to make AI poly app realizable in one of the largest markets of the world, India; when it is made meaningful to its end users.

More so in case of the visually challenged as they must have apps that provide them the correct object identification name as they move around looking for their daily needs.

The way advances in vision recognition allow robots to identify objects and wide range of applications, same way the AI should technologically advance.

AI could be designed and be more adaptive to the Indian consumers as this is where one of the largest population of the world resides.

Rapid progress in digital technologies and given the increasing use of technology and smart devices, there is a huge opportunity to create an impact through better usage experiences.

Our attempt may be just a granular bite of knowledge on the topic of concern but could be further enhanced by extending it to the other disability groups for an all-inclusive diverse India

\section{REFERENCES}

1. Liao, C.-F. (2013). Using a Smartphone Application to Support Visually Impaired Pedestrians at Signalized Intersection Crossings. Transportation Research Record: Journal of the Transportation Research Board. https://doi.org/10.3141/2393-02

2. Liao, C.-F. (2016). An Integrated Assistive System to Support Wayfinding and Situation Awareness for People with Vision Impairment. ProQuest Dissertations and Theses. 
3. Marmeleira, J., Laranjo, L., Marques, O., \& Pereira, C. (2014). Physical activity patterns in adults who are blind as assessed by accelerometry. Adapted Physical Activity Quarterly, 31(3), 283-296. https://doi.org/10.1123/apaq.20130039

4. Melarkode, S. G. (2014). THEIA: A collaborative, indoor navigation, smartphone application, for the visually impaired. ProQuest Dissertations and Theses.

5. Rahman, S., \& Hassan, Q. K. (2002). Object detection with vision based system: A secondary aid for visually impaired and blind people. In 6TH WORLD MULTICONFERENCE ON SYSTEMICS, CYBERNETICS AND INFORMATICS, VOL IX, PROCEEDINGS: IMAGE, ACOUSTIC, SPEECH AND SIGNAL PROCESSING II.

6. Gayathri, G., Vishnupriya, M., Nandhini, R., Banupriya, M., Al-barrm, O. B., Ersen, A., ... Alkunte, S. (2014). Smart Walking Stick for Visually Impaired. International Journal Of

7. Engineering And Computer Science. https://doi.org/10.1371/journal.pone.0015995 Terven, J. R., Salas, J., \& Raducanu, B. (2014). New Opportunities for computer visionbased assistive technology systems for the visually impaired. Computer. https://doi.org/10.1109/MC.2013.265

8. White, G. R., Fitzpatrick, G., \& McAllister, G. (2008). Toward accessible 3D virtual environments for the blind and visually impaired. In Proceedings of the 3rd international conference on Digital Interactive Media in Entertainment and Arts - DIMEA '08. https://doi.org/10.1145/1413634.1413663

9. Kapur, A., \& Kapur, S. (2014). Drishti: An ultra-low cost Visual-Aural assis-tive technology for the visually impaired. In i-CREATe 2014 - international Con-vention on Rehabilitation Engineering and Assistive Technology.

10. Tumkur, K., \& Subbiah, S. (2012). Modeling human walking for step detection and stride determination by 3-axis accelerometer readings in pedometer. In Pro-ceedings of International Conference on Computational Intelligence, Modelling and Simulation. https://doi.org/10.1109/CIMSim.2012.65

11. Paisios, N. (2012). Mobile accessibility tools for the visually impaired. ProQuest Dissertations and Theses.

12. Ben Gesing, Peterson, S. J., \& Michelsen, D. (2018). Artificial Intelligence in Logistics - A collaborative report by DHL and IBM on implications and use cases for the logistics industry. DHL Customer Solutions \& Innovation.

13. McGookin, D., Brewster, S., \& Jiang, W. (2008). Investigating touchscreen accessibility for people with visual impairments. In Pro-ceedings of the 5th Nordic conference on Humancomputerinteractionbuilding bridges - NordiCHI'08. https://doi.org/10.1145/1463160.1463193

14. Jafri, R., Ali, S. A., Arabnia, H. R., \& Fatima, S. (2014). Computer vision-based object recognition for the visually impaired in an indoors environment: a survey. Visual Computer. https://doi.org/10.1007/s00371-013-0886-1

15. Khairallah, M., Kahloun, R., Bourne, R., Limburg, H., Flaxman, S. R., Jonas, J. B., ... Taylor, H. R. (2015). Number of people blind or visually impaired by cataract worldwide and in world regions, 1990 to 2010. Investigative Ophthalmology and Visual Science. https://doi.org/10.1167/iovs.15-17201

16. Leasher, J. L., Bourne, R. R. A., Flaxman, S. R., Jonas, J. B., Keeffe, J., Naidoo, K., ... Taylor, H. R. (2016). Global estimates on the number of people blind or visually impaired by diabetic retinopathy: A meta-analysis from 1990 to 2010 . Diabetes Care. https://doi.org/10.2337/dc15-2171

17. Loomis, J. M., Golledge, R. G., Klatzky, R. L., Speigle, J. M., \& Tietz, J. (1994). Personal guidance system for the visually impaired. In Proceedings of the first annual ACM conference on Assistive technologies- Assets '94. https://doi.org/10.1145/191028.191051

18. Mahmud, N., Saha, R. K., Zafar, R. B., Bhuian, M. B. H., \& Sarwar, S. S. (2014). Vibration and voice operated navigation system for visually impaired person. In 2014 International Conferenceon Informatics,ElectronicsandVision,ICIEV2014. https://doi.org/10.1109/ICIEV.2014.6850740

19. https://www.thebetterindia.com/140639/artificial-intelligencevisually-impaired-drishti/

20. https://www.business-standard.com/article/economypolicy/govt-plans-to-launch-a-national-centre-for-artificialintelligence-119012901188_1.html

21. https://www.businesstoday.in/magazine/the-buzz/get-set-forthe-bot-era/story/304060.html

22. https://www.businesstoday.in/magazine/the-buzz/schoolingthem-differently/story/304056.html

23. https://www.businesstoday.in/magazine/the-buzz/the-futureoffice/story/304038.html 